\title{
TNF-Alpha Blockers in Inflammatory Bowel Diseases: Practical Recommendations and a User's Guide: An Update
}

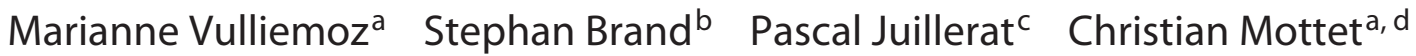 \\ Shomron Ben-Horin ${ }^{\mathrm{e}}$ Pierre Michetti ${ }^{\mathrm{a}}$ on behalf of the Swiss IBDnet, an official \\ working group of the Swiss Society of Gastroenterology \\ aCrohn's and Colitis Center, Gastroenterologie Beaulieu and Division of Gastroenterology and Hepatology, \\ CHUV, Lausanne, Switzerland; 'bivision of Gastroenterology and Hepatology, Department of Internal Medicine, \\ Kantonsspital Sankt Gallen, St. Gallen, Switzerland; 'Department of Visceral Surgery and Medicine, Bern University \\ Hospital, University of Bern, Bern, Switzerland; 'Centre sédunois de Gastroentérologie, Sion, Switzerland; \\ eInflammatory Bowel Disease Unit and Gastro-Immunology Laboratory Sheba Medical Center Tel-Aviv University, \\ Tel-Aviv, Israel
}

\section{Keywords}

TNF inhibitors · Biologicals · Crohn's disease $\cdot$ Ulcerative colitis $\cdot$ Infliximab $\cdot$ Inflammatory bowel diseases

\begin{abstract}
Background: Anti-tumour necrosis factor-alpha (anti-TNF) antagonists have been the mainstay in the treatment of inflammatory bowel diseases (IBDs) for over 20 years. Summary: This review article aimed to provide an update on recent advances in TNF antagonist therapy for IBDs. Key Messages: Their position in the treatment algorithm has evolved to "rapid step-up therapy" or "top-down therapy" according to disease severity and patients' characteristics. Limitations of anti-TNF antagonists include loss of response in up to 30 $50 \%$ of patients with or without the development of antibodies. Therapeutic drug monitoring should provide a tailored, personalized approach to this scenario. Recently, biosimilar agents have been approved for IBDs and are considered equivalent in efficacy to the originator.
\end{abstract}

(c) 2020 S. Karger AG, Basel

karger@karger.com

(c) 2020 S. Karger AG, Basel

www.karger.com/dig

Karger

\section{Introduction}

Inflammatory bowel diseases (IBDs), comprising Crohn's disease (CD) and ulcerative colitis (UC), are chronic, immunologically mediated disorders of the gut. The epidemiology of these conditions is changing [1]. Europe and North America have the highest reported incidence of IBDs, with a prevalence of more than $0.3 \%$. However, the incidence in newly industrialized cities in Africa, Asia, and South America is accelerating [2]. The natural history of IBDs is characterized by a relapsing, remitting disease course, which may lead to complications requiring hospitalization or surgery. The central goal of treatment is to reduce the risk of disease progression and surgery by achieving clinical and endoscopic remission. Therefore, recently, the paradigm of treatment has shifted to using biologicals as "top-down therapy" or "rapid step-up therapy" in those with severe disease phenotype [3-9]. The anti-tumour necrosis factor (antiTNF) antagonist infliximab (IFX) was the first biological approved for IBDs in the United States in 1998 for CD 
Table 1. Summary of anti-TNF inhibitors available for the treatment of IBDs

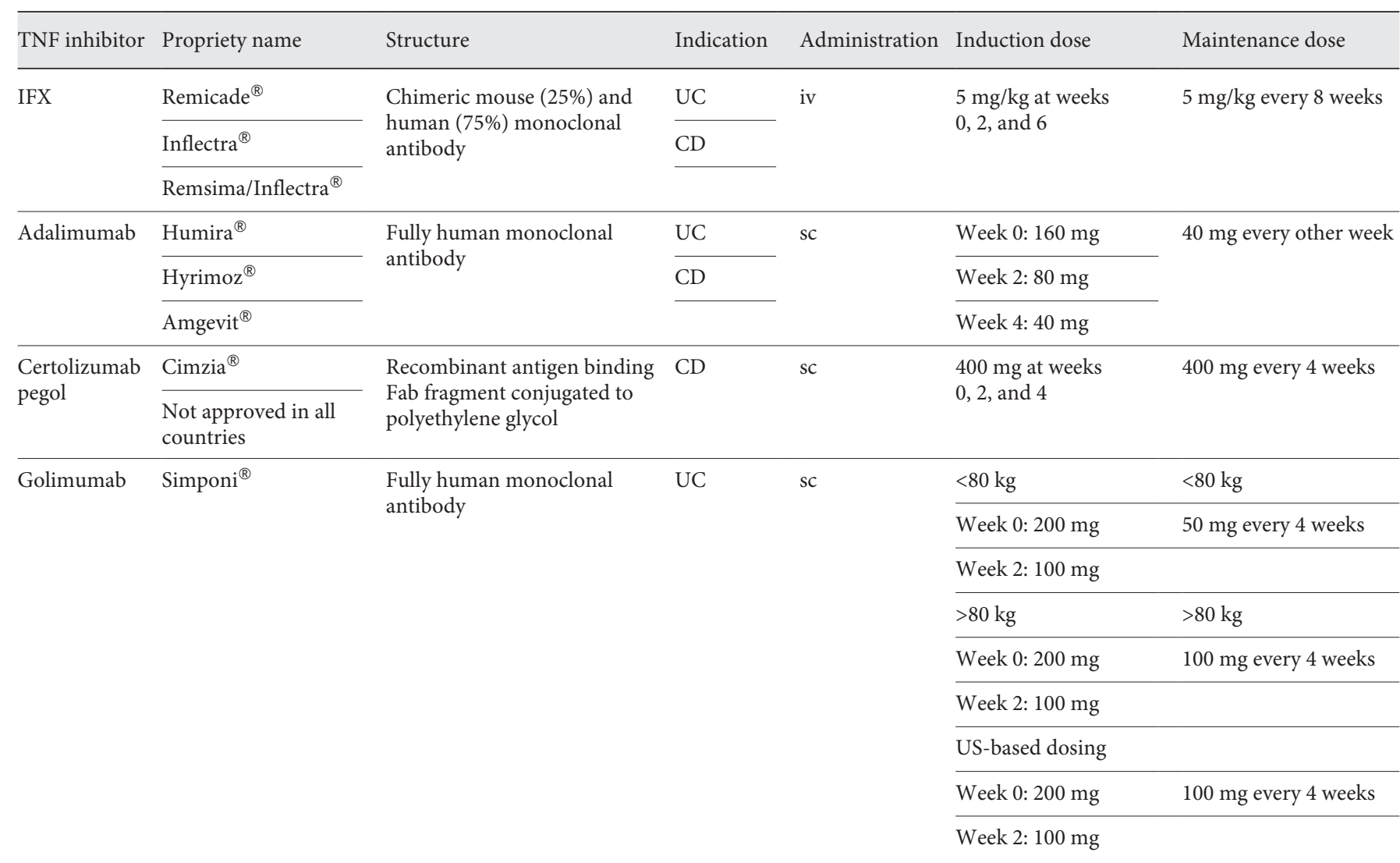

TNF, tumour necrosis factor; IBDs, inflammatory bowel diseases; UC, ulcerative colitis; CD, Crohn's disease.

and in 2005 for UC. It represented a breakthrough in patient care, followed by adalimumab and other members of this class, but not without limitations such as loss of response in $30-50 \%$ of patients [10] and increased risk of serious infection[11] (Table 1).

\section{TNF Inhibitors Used in IBDs}

\section{Indications for TNF Inhibitors}

Crohn's Disease

European consensus guidelines [12] and the American College of Gastroenterology guidelines list similar indications [13] for TNF inhibitors for CD, which include

- steroid refractory or dependant disease,

- immunomodulator refractory disease,

- severely active disease with adverse prognostic factors, and

- fistulizing disease.

TNF-Alpha Blockers in Inflammatory Bowel Diseases: A User's Guide
Negative prognostic factors for CD include disease onset below age 40 years, perianal disease, active smoking, prior intestinal surgical resection, need for steroids at diagnosis, stricturing disease, and small intestinal disease [12].

Ulcerative Colitis [14, 15]

Indications for TNF inhibitors in UC include

- steroid refractory severe colitis,

- steroid-dependent active colitis,

- oral steroid refractory disease, and

- immunomodulator refractory disease.

Negative prognostic factors for UC include disease onset at the age of $<16$ years, C-reactive protein (CRP) $>10$ $\mathrm{mg} / \mathrm{L}$ after 1 year of extensive colitis, and admission for acute severe colitis $[16,17]$.

More recently, there has been a shift in the treatment paradigm towards an "accelerated step-up" approach according to the presence of prognostic factors and disease 
phenotype [5-9]. Initiating anti-TNF treatment in early $\mathrm{CD}$, in patients with less than 2 years of disease duration, may be associated with superior efficacy, as compared to introduction of these medications later in the disease course $[6,8,9]$. The REACT study was an open-label cluster randomization study of $1,727 \mathrm{CD}$ patients treated in 41 clinics, which examined treatment outcomes in patients receiving early biological treatment, as compared to patients on conventional therapy. Although primary outcomes were similar in patients with early combined therapy and biological monotherapy, the secondary outcomes of time to first hospitalization and time to surgery were longer in the combined therapy group than the monotherapy group [6].

Combination Therapy of anti-TNF Agents with

Immunomodulators

Combination therapy of IFX and an immunomodulator in biological and immunomodulator-naïve patients is more efficacious than monotherapy and is associated with superior clinical and endoscopic outcomes. This was first shown in the SONIC study [18], a double-blinded, placebo-controlled, prospective clinical trial that demonstrated superior steroid-free remission and mucosal healing rates in the combination IFX and immunomodulator arm as compared to the IFX monotherapy arm (and also compared to the immunomodulator arm). A post hoc analysis indicated that this effect was no longer present when corrected for IFX trough concentrations, suggesting that the superior efficacy may be due to improved pharmacokinetics of IFX rather than a synergistic effect [19]. Similarly, the SUCCESS study demonstrated that the same combination therapy in UC was associated with superior mucosal healing and steroid-free remission rates [20]. Few data exist for the combination therapy with adalimumab. The DIAMOND study was a prospective, open-label study, which demonstrated a shorter time to mucosal healing in CD patients treated with combined adalimumab and an immunomodulator, than adalimumab monotherapy, but there was no significant difference in clinical and endoscopic remission at week 52 [21].

However, combination therapy alters the safety profile of therapy and is associated with a higher risk of opportunistic infection [22] and neoplasms such as lymphoma and non-melanoma skin cancer $[11,22]$. A systematic review demonstrated that the overall risk of hepato-splenic T-cell lymphoma in males aged less than 35 years receiving combination therapy is dramatically increased to an absolute risk of 1:3,534, compared to the absolute risk of 1:7,404 for males aged under 35 years on thiopurines alone, 1:21,945 for all patients on thiopurines and biologics, and 1:45,000 for all patients on thiopurines [14]. The PYRAMID registry followed more than 5,000 patients with CD treated with adalimumab for 7 years. There was a significant increased risk of serious infection (12.7 vs. $9.6 \%, p=0.007)$ and lymphoma ( 3.1 vs. $1.9 \%, p=0.014$ ) in those patients treated with combination therapy compared to monotherapy [23]. The ENCORE registry was a prospective, observational 5-year study of 2,960 IFX-naïve CD patients [24]. Serious infection rate was not increased in the combination therapy group. However, the lymphoproliferative disorder rate was higher (14.5/1,000 patient years vs. 7.0/1,000 patient years). Furthermore, in a French cohort study of 189,289 IBD patients, the observed risk of lymphoma was mildly elevated in patients receiving thiopurine monotherapy or anti-TNF inhibitor monotherapy, while combination therapy was associated with a higher risk [25].

Lower levels of thiopurines appear to be sufficient to achieve therapeutic IFX levels. For thiopurine monotherapy, the literature suggests that 6-thioguanine (TGN) levels greater than $235 \mathrm{pmol} / 8 \times 10$ [8] RBCs are linked to improved clinical outcomes [26]. In combination therapy, one study found that a level of 6-TGN of $125 \mathrm{pmol} / 8$ $\times 10$ [8] RBCs or greater may be correlated with therapeutic levels of IFX [27]. These findings are compatible with another study which demonstrated that a level of 6-TGN $<105 \mathrm{pmol} / 8 \times 10^{8} \mathrm{RBCs}$ is associated with unfavourable IFX pharmacokinetics [28]. However, conflicting results suggest that higher levels of 6-TGN are needed [29]. Similarly, higher methotrexate doses, in combination with IFX, were associated with better outcomes [30].

In conclusion, combination therapy of thiopurines with IFX in the selected patient population (with severe or fistulizing disease, naïve to both) is associated with superior clinical and endoscopic outcomes. It remains debatable if lower doses of thiopurines are adequate to achieve this goal, with similar IFX trough levels. The benefits of combination therapy should be balanced with its decreased safety profile. Caution should be taken in specific patient population who have higher risk when exposed to thiopurines, such as young males, patients who are Epstein-Barr virus seronegative [14], or patients over 65 years who are at an increased risk of infection or lymphoma [31]. Combination therapy with methotrexate may be considered in these cases [32].

\section{Contraindications and Precaution}

The relative or absolute contraindications of TNF inhibitors can be summarized by the acronym "STOIC":
18

Digestion 2020;101(suppl 1):16-26 DOI: $10.1159 / 000506898$
Vulliemoz/Brand/Juillerat/Mottet/ Ben-Horin/Michetti 
Table 2. Screening for infections before initiation of TNF inhibitor treatment

\begin{tabular}{lll}
\hline Systemic viruses & Pathogens in the stool & Bacteria \\
\hline Hepatitis B serology & Clostridium difficile & Mycobacterium tuberculosis \\
\cline { 2 - 3 } & Other bacteria, viruses, and parasites & Interferon gamma release assay \\
\cline { 2 - 3 } & & Chest X-ray \\
\hline Hepatitis C serology & \\
\hline Epstein-Barr virus serology & \\
\hline Cytomegalovirus serology & \\
\hline HIV serology
\end{tabular}

Sepsis/abscess, Tuberculosis, Optic neuritis (demyelination), Infusion reaction (anaphylaxis), Cancer/lymphoma and Congestive heart failure (Stages III and IV) [33].

\section{Prebiological Treatment Screening}

- Before prescribing TNF inhibitors, a thorough history is necessary in order to exclude the contraindications mentioned above.

- Verification and update of vaccinal status for hepatitis $B$, hepatitis A, varicella, and human papillomavirus (HPV) should be performed before starting treatment. (Refer to the article by Manser et al. in this issue of $D i$ gestion.)

- Regarding potential infectious complications, the European Crohn's and Colitis Organization (ECCO) offers a detailed checklist for the prevention of infections, which should be completed before initiating therapy [34] (Table 2).

- Baseline laboratory tests, such as full blood count, liver function tests, CRP, and renal function, should be performed in addition to documenting objective measures of disease activity such as faecal calprotectin \pm endoscopy with histology, and imaging.

\section{Administration of IFX}

Infusion Protocols

- Product information advises a graded stepwise increase of the infusion rate of IFX with induction.

- The duration of the infusion may then be shortened to $2 \mathrm{~h}$ if it is well tolerated and further to $1 \mathrm{~h}$ during maintenance therapy $[35,36]$. Data exist that perhaps less monitoring is required post-infusion [37].

TNF-Alpha Blockers in Inflammatory

Bowel Diseases: A User's Guide
Subcutaneous IFX

A subcutaneous formulation of the IFX biosimilar (BS) CT-P13 (Celltrion) may soon be available for phase 3 clinical studies in the rheumatoid arthritis population [38], and a phase 1 study in the CD population has been recently conducted [39].

Monitoring Safety and Managing Adverse Effects

The adverse effects of anti-TNF inhibitors may be classified as infectious and non-infectious. The non-infectious side effects include but are not limited to increased risk of malignancies such as lymphoma and melanoma and local or systemic reactions related to administration of the drug.

\section{Infusion Reactions and Premedication}

Immediate-type reactions are reactions that occur within the course of the infusion, up to $2 \mathrm{~h}$ after. These reactions may occur in up to 5-23\% of IBD patients [40]. Reactions vary from anaphylaxis to pruritus, flushing, chest discomfort, headache, dizziness, and rash [40, 41]. It is postulated that the reaction results from cytokine release and/or direct mast cell degranulation due to the rapid infusion rate (Table 3 ).

Late infusion reactions manifest as serum sicknesstype reactions, such as arthralgia, joint stiffness, fever, malaise, and, in severe events, also immune-complexmediated renal failure. The symptoms develop within 1-3 weeks after administration of the drug. Treatment is symptomatic with analgesia and antihistamine. For severe symptoms, a short course of oral corticosteroids may be necessary.

The aetiology of infusion reactions is uncertain [40]. The underlying mechanisms may include massive pro- 
Table 3. Management of IFX infusion reactions

\begin{tabular}{|c|c|}
\hline Reaction type & Management \\
\hline \multirow[t]{2}{*}{ Mild } & 1. Observation \\
\hline & 2. Reduce rate of the infusion \\
\hline \multirow[t]{3}{*}{ Moderate } & 1. Stop the infusion until symptoms resolve \\
\hline & $\begin{array}{l}\text { 2. Symptomatic treatment - analgesics and } \\
\text { antihistamines }\end{array}$ \\
\hline & $\begin{array}{l}\text { 3. Restart the infusion at } 10 \mathrm{~mL} / \mathrm{h} \text { with a gradual } \\
\text { increase every } 15 \mathrm{~min} \text { until the maximal rate } \\
\text { tolerated is reached }\end{array}$ \\
\hline \multirow{6}{*}{$\begin{array}{l}\text { Severe life- } \\
\text { threatening }\end{array}$} & 1. Stop infusion immediately \\
\hline & $\begin{array}{l}\text { 2. Maintenance of airway, breathing, and } \\
\text { circulation is a priority }\end{array}$ \\
\hline & $\begin{array}{l}\text { 3. Administration of adrenaline } 0.5 \mathrm{mg}: 100 \\
\text { intramuscular injection }\end{array}$ \\
\hline & 4. Elevation of legs \\
\hline & 5. IFX should be discontinued \\
\hline & $\begin{array}{l}\text { 6. If no alternative therapy exists, rapid } \\
\text { desensitization may be performed }\end{array}$ \\
\hline
\end{tabular}

inflammatory and vasoactive cytokine release, IgE-mediated type I hypersensitivity reactions, IgG anaphylaxis, complement activation, and mast cell and basophil degranulation. The risk of developing infusion reactions is associated with increasing drug intervals and drug holidays [42]. A paucity of evidence exists on whether prophylactic premedication reduces the risk of infusion reaction, and no consensus guidelines exist. Hence, physician practices are variable $[43,44]$. Premedication may include paracetamol, diphenhydramine, and/or corticosteroids and, in general, may be prescribed to target specific symptoms of infusion reactions such as urticaria, fever, and myalgia [40]. If moderate reaction occurs, premedication with oral steroids $24 \mathrm{~h}$ before drug administration with antihistamine has been one proposed approach [40].

\section{Infectious Complications}

TNF inhibitors are associated with an increased risk of infection [45-47]. The Crohn Therapy, Resource, Evaluation, and Assessment Tool (TREAT) registry was a prospective, observational registry of $\mathrm{CD}$ patients which was created in 2006. A 13-year follow-up analysis of the registry revealed a rate of serious infections of
$2.15 / 100$ patient years in patients receiving IFX, yielding a relative risk of $2.46(1.80-3.36,95 \%$ confidence interval). Notably, the most common serious infection was pneumonia, highlighting the importance of immunization. Risk factors for serious infections included prednisone and narcotic use, duration and severity of disease, and IFX use. Age was not identified as a risk factor [47]. The 2014 Second ECCO Consensus on the prevention, diagnosis, and management of opportunistic infections in IBDs presents a detailed practical approach to prevention and management of infections during TNF inhibitor treatment [34].

\section{Malignancy}

TNF inhibitors are associated with an increased risk of hepato-splenic T-cell lymphoma, and melanoma [4851]. A 13-year follow-up of the TREAT registry patients revealed that the proportion of patients developing neoplasms was similar in the IFX-treated group and the other treatment group [47]. There was one incidence of Tcell hepato-splenic lymphoma in a patient who received a single dose of IFX after having received 3 years of thiopurines.

The ECCO consensus on IBDs and malignancy advises that the risk of developing hepato-splenic T-cell lymphoma can be reduced by limiting combination therapy with thiopurines to a duration of less than 2 years [50]. In terms of the increased risk of melanoma, annual skin examination and application of sunscreen are recommended. The consensus states that "TNF inhibition alone does not increase overall cancer risk in IBD patients." However, a recent study demonstrated that anti-TNF monotherapy was associated with a small but statistically significant increased risk of lymphoma [25]. In the case of a diagnosis of malignancy during TNF inhibitor therapy, the patient's situation should be discussed in a multidisciplinary setting. General recommendations include stopping immunosuppressants during cytotoxic chemotherapy. Should a flare occur, treatments with aminosalicylates, local steroids, and nutritional therapies are recommended. Other IBD treatments can be considered on a case-by-case basis [50].

\section{Additional Adverse Effects}

Other documented adverse effects have been reported, such as demyelinating disease, worsening of cardiomyopathy, paradoxical psoriasis and other skin lesions, liver dysfunction, and autoimmune diseases such as systemic lupus erythematosus, vasculitis, and polyarthritis [5254]. 
Long-Term Preventative Care for Patients Receiving TNF Inhibitors

The following measures are recommended to reduce potential adverse reactions of TNF inhibitors $[13,34,55]$ :

- Vaccination status and update should be evaluated and performed before starting therapy.

- Patients should receive an annual influenza vaccine and a 5-yearly pneumococcal vaccine.

- Vaccines for diphtheria, tetanus, hepatitis B, and HPV should be administered according to national guidelines. (Refer to the article by Manser et al. in this issue of Digestion.)

- Live vaccines such as those against oral polio; rotavirus; measles, mumps, and rubella; yellow fever; and varicella should be avoided at least 4 weeks before immunosuppression.

- Women should undergo annual cervical cancer screening and receive vaccination against HPV $\left(\right.$ Gardasil $\left.{ }^{\circledR}\right)$.

- Patients should have a dermatological exam for melanoma (TNF inhibitors) and non-melanoma skin cancers (if on combination therapy with thiopurines) every $1-2$ years.

- Women should undergo pre-pregnancy counselling. A possible approach is discussed in the recent guidelines published by the American Gastroenterology Association [56].

- Full blood count, liver function tests, and renal function should be undertaken every 3-4 months.

\section{Monitoring and Optimizing Response}

The goals of treatment are to achieve clinical remission and endoscopic remission, while histological remission may be considered an adjunct goal [57]. As higher TNF inhibitor concentrations have been associated with favourable clinical outcomes and being cost effective, there has been a shift in the paradigm of treatment of IBDs to tailored therapy with dose optimization-based therapeutic drug levels (therapeutic drug monitoring [TDM]). Proactive TDM, performed for dose optimization which may be performed at fixed time points such as after drug induction in patients in clinical remission, may also be associated with superior clinical outcomes [58].

Indications for TDM after successful induction therapy include secondary loss of response and consideration of a drug holiday $[58,59]$. The efficacy of anti-TNF inhibitors is limited by loss of response in $30-50 \%$ of patients [10]. Determining the trough level and measuring anti-drug antibodies (ADAs) determine if the loss of response is due to subtherapeutic levels (reactive TDM). TDM may also be performed when the patient is in remission in order to optimize dosing to potentially prevent a flare or loss of response (proactive TDM), for example, at the end of induction or during maintenance. A retrospective study of 83 patients evaluated the frequency of IFX discontinuation in 3 groups of IBD patients treated with IFX: those receiving IFX monotherapy as the standard of care, those receiving IFX monotherapy who had proactive TDM, and those treated with combination therapy. The frequency of IFX discontinuation was lower in the proactive TDM group than the monotherapy standard of care group. Additionally, there was no difference in IFX discontinuation in the proactive TDM group and those receiving combination therapy, suggesting that in patients receiving monotherapy, proactive TDM may improve IFX treatment durability [60]. These results were mirrored in a study of 149 IBD patients which showed that IFX monotherapy with dose optimization by proactive TDM was as clinically effective as the combination therapy [61].

Many consensus recommendations and therapeutic guidelines have been published on TDM [58, 59, 62, 63]. The most recent consensus statement [58] recommended IFX levels of $3-8 \mu \mathrm{g} / \mathrm{mL}$ at week 14 and adalimumab trough concentrations of $5-12 \mu \mathrm{g} / \mathrm{mL}$ at week 4 to achieve clinical remission. The minimum concentration for certolizumab pegol at week 6 should be $>32 \mu \mathrm{g} / \mathrm{mL}$ and for golimumab at week $6>2.5 \mu \mathrm{g} / \mathrm{mL}$ [58]. However, therapeutic ranges differ between disease phenotypes and inflammatory burdens. For example, perianal CD fistula healing requires higher IFX trough levels above $10 \mu \mathrm{g} / \mathrm{mL}$ $[59,64,65]$.

If low-titre $\mathrm{ADAs}$ are detected, a repeat assay in 2 months may be considered to determine if the ADAs are transient or persistent. High-titre ADAs with no detectable trough drug levels are virtually always persistent, but the threshold of "high titre" versus "low titre" needs to be established for each assay, as the ADA thresholds are assay-specific. Recent consensus statements suggest that detection of ADAs in the presence of adequate trough levels is unlikely to be significant.

\section{Special Situations}

Pregnancy and Lactation

Consensus guidelines such as the Toronto Consensus Statements for the Management of IBD, the ECCO Guidelines for Reproduction, and the IBD in Pregnancy Clinical Care Pathway contain detailed evidence-based recommendations $[56,66,67]$. All 3 references state that TNF inhibitors can be continued throughout pregnancy and that this is associated with reduced risk of flares and lower risk of adverse pregnancy outcomes. The clinical care 
pathway proposes that the last dose in the third trimester is timed so that a trough is present at the time of delivery, while the ECCO guidelines propose stopping at week 24 . Certolizumab pegol is the only TNF inhibitor that does not cross the placenta [68] and is approved for use in pregnancy. Live vaccines for the baby should be withheld for 6 months post-partum. TNF inhibitors are considered safe in lactation. (For more details, see the article by Restellini et al. in the current issue of Digestion.)

\section{Surgery}

A recent systematic review and meta-analysis showed that preoperative exposure to anti-TNF has been associated with a higher risk of peri- and post-operative complications [69]. Therefore, perioperative management of TNF inhibitors varies from stopping the agents at least 4 weeks preoperatively [70], to timing the surgery when the drug is at a trough level [71]. In principle, the urgency of the surgery should be evaluated. If elective surgery is considered, the decision for interruption of treatment should be individualized and surgery should ideally occur when the TNF inhibitor trough level is at its lowest [71-73]. TNF inhibitors can be resumed once post-operative infectious complications have been excluded.

\section{Biosimilars and Switching}

BSs of anti-TNF agents are now available for IFX and adalimumab. The efficacy and safety of the first IFX BS, CT-P13, have been established for rheumatological indications and followed by approval in IBDs by extrapolation of indications. Several post-marketing studies evaluating the efficacy of CT-P13 in IBDs have then been performed. The largest study, known as the NOR-SWITCH study, evaluated switching from originator to CT-P13 in patients with chronic inflammatory disease, including IBDs, who were stable on IFX therapy. It was a doubleblinded, non-inferiority trial where patients were randomized to be switched to CT-P13 or to continue current IFX therapy $[74,75]$. The proportion of patients with disease worsening was not significantly different between the groups, but in a subanalysis the absolute difference was larger in the $\mathrm{CD}$ group, which may raise questions about the interchangeability of this compound in CD [76]. CT-P13 is known for a decreased affinity for the Fc $\gamma$ RIII receptors [76], which may in part explain this result, although other studies using more physiologically relevant serum in the assays have shown similar results for CT-P13 and originator IFX [77, 78]. Moreover, in a recently published phase III randomized controlled study in CD, the efficacy of CT-P13 and originator IFX was comparable for induction and maintenance of remission [79]. A large cohort study performed on the French nationwide health administrative database found no difference in a composite outcome in 5,050 patients exposed 1:1 to IFX originator or to BS CT-P13 after a median follow-up of 1 year [80]. Based on these results and on other case series, switching from IFX originator to CT-P13 may be considered equivalent to continuing IFX originator for IBD patients. Existing IBD-specific literature is lacking for SB2, another IFX BS currently available in some jurisdictions, and for adalimumab BSs, but data should be available soon.

\section{Stopping and De-Escalation}

In patients who have achieved deep remission (a sustained relapse-free and steroid-free period in the presence of mucosal healing), safety concerns, risk of infectious complications, and neoplasia, as well as pregnancy and economic issues drive de-escalation or stopping strategies for anti-TNFs. However, stopping any therapy in IBDs is associated with an increased risk of relapse. A comprehensive ECCO topical review is now available on stopping therapy [81]. In a landmark article, the STORI trial by Louis et al. [82] stopped IFX in patients who were in deep remission for at least 6 months after receiving 1 year of combination IFX/antimetabolite treatment. They observed a 1-year relapse rate of $43.9 \%$ and identified male gender, absence of surgical resection, leucocytosis, elevated CRP or calprotectin, and drug levels $>2 \mu \mathrm{g} / \mathrm{mL}$ as risk factors with a cumulative effect on relapse [82]. A similar rate was found in a meta-analysis of 27 studies including IFX and adalimumab withdrawal trials, in which about one-third of patients with IBDs relapsed after 1 year, a proportion that increased to a half in the long term $[83,84]$. Patients in long-standing remission without prior need for dose escalation are the best candidates for deescalation. Maintenance of immunomodulator therapy appears to reduce the risk of relapse [84]. De-escalation can be performed but should be monitored by measuring the trough levels of the drug. De-escalation or stopping is not recommended in fistulizing CD [81, 83, 84]. In general, however, reintroduction of the same agent upon relapse is successful.

\section{Conclusion}

TNF inhibitors have been the cornerstone of IBD therapy for many years. There has been a shift in their position in the treatment algorithm to prescribing them
Vulliemoz/Brand/Juillerat/Mottet/ Ben-Horin/Michetti 


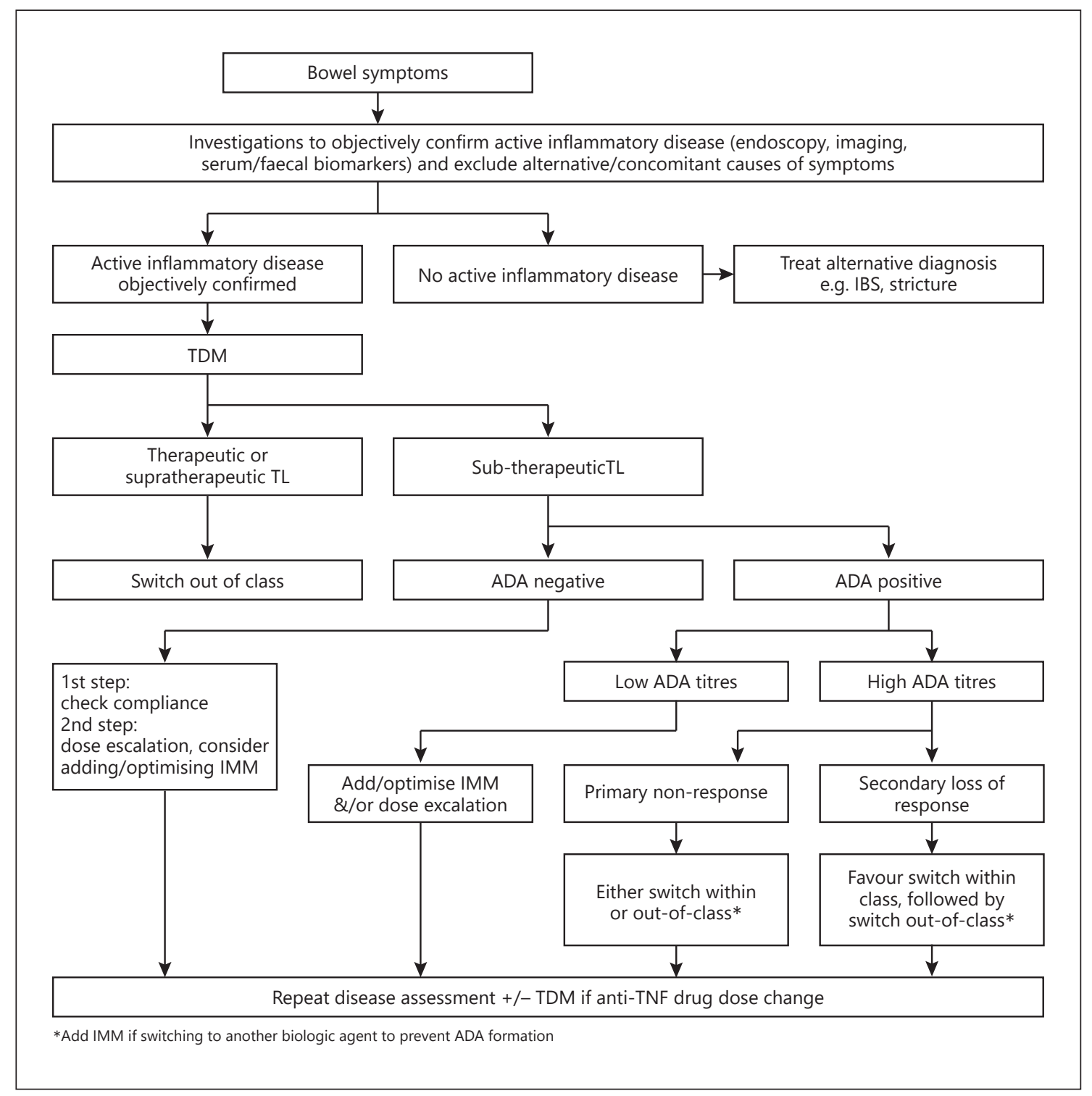

Fig. 1. Proposed algorithm for TDM [59]. TDM, therapeutic drug monitoring.

early according to disease severity and negative prognostic factors. Combination therapy with thiopurines is superior to monotherapy in patients naïve to both but should be prescribed with caution in males less than 35 years of age, in patients who are Epstein-Barr virus negative, and in the elderly. Tight disease control including monitoring symptoms, calprotectin, and CRP as well as TDM can optimize medical treatment. BSs are now available and are considered equally efficacious as the originators.

TNF-Alpha Blockers in Inflammatory Bowel Diseases: A User's Guide

\section{Disclosure Statement}

P.M. received consulting fees from Calypso, Ferring Pharmaceuticals, Merck Serono, MSD, Nestlé Health Sciences, Pfizer, Takeda, UCB Pharma, and Vifor Pharma and lecture fees from AbbVie, Ferring Pharmaceuticals, Hospira, MSD, Takeda, UCB Pharma, and Vifor Pharma. P.J. has no conflicts of interest to declare. M.V. received lecture fees from Takeda and Vifor. S.B. received consulting fees from AbbVie, Janssen-Cilag AG, MSD, Pfizer, Takeda, UCB Pharma, and Vifor Pharma. C.M. received consulting fees from Vifor, Takeda, and Abbvie. S.B.H. received consultancy and/or research support from Abbvie, Takeda, Celltrion, Janssen, Pfizer, and GSK. 


\section{Funding Sources}

No external funds were used for the preparation of the manuscript. The foundation for digestive and hepatic diseases in Lausanne covered the copyright transfer for the reproduction of Figure 1.

\section{Author Contributions}

M.V. wrote the first draft of the manuscript. All co-authors contributed comments, revisions, and contributions to the literature search, till the final version was achieved.

\section{References}

1 Coskun M, Nielsen OH. Tumor necrosis factor inhibitors for inflammatory bowel disease. N Engl J Med. 2013;369(26):2561-2.

2 Ng SC, Shi HY, Hamidi N, Underwood FE, Tang W, Benchimol EI, et al. Worldwide incidence and prevalence of inflammatory bowel disease in the 21st century: a systematic review of population-based studies. Lancet. 2018;390(10114):2769-78.

3 Adegbola SO, Sahnan K, Warusavitarne J, Hart A, Tozer P. Anti-TNF therapy in Crohn's disease. Int J Mol Sci. 2018;19(8):2244.

4 Cohen BL, Sachar DB. Update on anti-tumor necrosis factor agents and other new drugs for inflammatory bowel disease. BMJ. 2017;357: j2505.

5 Colombel JF, Panaccione R, Bossuyt P, Lukas $\mathrm{M}$, Baert $\mathrm{F}$, Vaňásek $\mathrm{T}$, et al. Effect of tight control management on Crohn's disease (CALM): a multicentre, randomised, controlled phase 3 trial. Lancet. 2018;390(10114): 2779-89.

6 Khanna R, Bressler B, Levesque BG, Zou G, Stitt LW, Greenberg GR, et al. Early combined immunosuppression for the management of Crohn's disease (REACT): a cluster randomised controlled trial. Lancet. 2015; 386(10006):1825-34.

7 Peyrin-Biroulet L, Fiorino G, Buisson A, Danese S. First-line therapy in adult Crohn's disease: who should receive anti-TNF agents? Nat Rev Gastroenterol Hepatol. 2013;10(6): 345-51.

8 Danese S, Fiorino G, Peyrin-Biroulet L. Early intervention in Crohn's disease: towards disease modification trials. Gut. 2017;66(12): 2179-87.

9 D’Haens G, Baert F, van Assche G, Caenepeel $\mathrm{P}$, Vergauwe P, Tuynman H, et al. Early combined immunosuppression or conventional management in patients with newly diagnosed Crohn's disease: an open randomised trial. Lancet. 2008;371(9613):660-7.

10 Ben-Horin S, Chowers Y. Review article: loss of response to anti-TNF treatments in Crohn's disease. Aliment Pharmacol Ther. 2011;33(9):987-95.

11 Lichtenstein GR. The TREAT registry: evolution of knowledge from 1999 to 2017: lessons learned. Clin Gastroenterol Hepatol. 2017; 15(9):1319-21.

12 Gomollón F, Dignass A, Annese V, Tilg H, Van Assche G, Lindsay JO, et al. 3rd European evidence-based consensus on the diagnosis and management of Crohn's disease 2016: part 1: diagnosis and medical management. J Crohns Colitis. 2017;11(1):3-25.
13 Lichtenstein GR. New ACG guideline for the management of Crohn's disease. Gastroenterol Hepatol. 2018;14(8):451.

14 Kotlyar DS, Osterman MT, Diamond RH, Porter D, Blonski WC, Wasik M, et al. A systematic review of factors that contribute to hepatosplenic T-cell lymphoma in patients with inflammatory bowel disease. Clin Gastroenterol Hepatol. 2011;9(1):36-41 e1.

15 Rubin DT, Ananthakrishnan AN, Siegel CA, Sauer BG, Long MD. ACG clinical guideline: ulcerative colitis in adults. Am J Gastroenterol. 2019;114(3):384-13.

16 Reinisch W, Reinink AR, Higgins PD. Factors associated with poor outcomes in adults with newly diagnosed ulcerative colitis. Clin Gastroenterol Hepatol. 2015;13(4):635-42.

17 Magro F, Gionchetti P, Eliakim R, Ardizzone S, Armuzzi A, Barreiro-de Acosta M, et al. Third European evidence-based consensus on diagnosis and management of ulcerative colitis. Part 1: definitions, diagnosis, extra-intestinal manifestations, pregnancy, cancer surveillance, surgery, and ileo-anal pouch disorders. J Crohns Colitis. 2017;11(6):649-70.

18 Colombel JF, Sandborn WJ, Reinisch W, Mantzaris GJ, Kornbluth A, Rachmilewitz D, et al. Infliximab, azathioprine, or combination therapy for Crohn's disease. N Engl J Med. 2010;362(15):1383-95.

19 Colombel JF, Adedokun OJ, Gasink C, Gao LL, Cornillie FJ, D’Haens GR, et al. Combination therapy with infliximab and azathioprine improves infliximab pharmacokinetic features and efficacy: a post hoc analysis. Clin Gastroenterol Hepatol. 2018;17(8):1525$32 \mathrm{e} 1$.

20 Panaccione R, Ghosh S, Middleton S, Márquez JR, Scott BB, Flint L, et al. Combination therapy with infliximab and azathioprine is superior to monotherapy with either agent in ulcerative colitis. Gastroenterology. 2014; 146(2):392-e3.

21 Matsumoto T, Motoya S, Watanabe K, Hisamatsu T, Nakase H, Yoshimura N, et al. Adalimumab monotherapy and a combination with azathioprine for Crohn's disease: a prospective, randomized trial. J Crohns Colitis. 2016;10(11):1259-66.

22 Lichtenstein GR, Rutgeerts P, Sandborn WJ, Sands BE, Diamond RH, Blank M, et al. A pooled analysis of infections, malignancy, and mortality in infliximab- and immunomodulator-treated adult patients with inflammatory bowel disease. Am J Gastroenterol. 2012; 107(7):1051-63.
23 D'Haens G, Reinisch W, Panaccione R, Satsangi J, Petersson J, Bereswill M, et al. Lymphoma risk and overall safety profile of adalimumab in patients with crohn's disease with up to 6 years of follow-up in the pyramid registry. Am J Gastroenterol. 2018;113(6):87282.

24 D’Haens G, Reinisch W, Colombel JF, Panes J, Ghosh S, Prantera C, et al. Five-year safety data from ENCORE, a european observational safety registry for adults with Crohn's disease treated with infliximab [Remicade ${ }^{\circledast}$ or conventional therapy. J Crohns Colitis. 2017; 11(6):680-9.

25 Lemaitre M, Kirchgesner J, Rudnichi A, Carrat F, Zureik M, Carbonnel F, et al. Association between use of thiopurines or tumor necrosis factor antagonists alone or in combination and risk of lymphoma in patients with inflammatory bowel disease. JAMA. 2017; 318(17):1679-86

26 Dubinsky MC, Lamothe S, Yang HY, Targan SR, Sinnett D, Théorêt $Y$, et al. Pharmacogenomics and metabolite measurement for 6-mercaptopurine therapy in inflammatory bowel disease. Gastroenterology. 2000;118(4): 705-13.

27 Yarur AJ, Kubiliun MJ, Czul F, Sussman DA, Quintero MA, Jain A, et al. Concentrations of 6-thioguanine nucleotide correlate with trough levels of infliximab in patients with inflammatory bowel disease on combination therapy. Clin Gastroenterol Hepatol. 2015; 13(6):1118-e3.

28 Roblin X, Boschetti G, Williet N, Nancey S, Marotte $\mathrm{H}$, Berger A, et al. Azathioprine dose reduction in inflammatory bowel disease patients on combination therapy: an open-label, prospective and randomised clinical trial. Aliment Pharmacol Ther. 2017;46(2):142-9.

29 Kariyawasam VC, Ward MG, Blaker PA, Patel KV, Goel R, Sanderson JD, et al. Thiopurines dosed to a therapeutic 6-thioguanine level in combination with adalimumab are more effective than subtherapeutic thiopurine-based combination therapy or adalimumab monotherapy during induction and maintenance in patients with long-standing Crohn's disease. Inflamm Bowel Dis. 2017; 23(9):1555-65

30 Colman RJ, Rubin DT. Optimal doses of methotrexate combined with anti-TNF therapy to maintain clinical remission in inflammatory bowel disease. J Crohns Colitis. 2015; 9(4):312-7. 
31 Beaugerie L. Lymphoma: the bête noire of the long-term use of thiopurines in adult and elderly patients with inflammatory bowel disease. Gastroenterology. 2013;145(5):927-30.

32 Feagan BG, McDonald JW, Panaccione R, Enns RA, Bernstein CN, Ponich TP, et al. Methotrexate in combination with infliximab is no more effective than infliximab alone in patients with Crohn's disease. Gastroenterology. 2014;146(3):681-e1.

33 Cummings JR, Keshav S, Travis SP. Medical management of Crohn's disease. BMJ. 2008; 336(7652):1062-6.

34 Rahier JF, Magro F, Abreu C, Armuzzi A, Ben-Horin S, Chowers Y, et al. Second European evidence-based consensus on the prevention, diagnosis and management of opportunistic infections in inflammatory bowel disease. J Crohns Colitis. 2014;8(6):443-68.

35 Neef HC, Riebschleger MP, Adler J. Metaanalysis: rapid infliximab infusions are safe. Aliment Pharmacol Ther. 2013;38(4):365-76.

36 Saxena P, Chen G, Jideh B, Collins G, Leong RW. Safety and cost benefit of an accelerated infliximab infusion protocol in the treatment of ambulatory patients with inflammatory bowel diseases. Expert Opin Biol Ther. 2014; 14(3):277-82.

37 Robinson KWA, Marshall L, Lobo A. N803 Accelerated infusions of biosimilar infliximab are safe and well tolerated and monitoring post infusion is not required. J Crohn's Colitis. 2017;11(Suppl_1):S492-3.

38 Westhovens RYDH, Jaworski J, MatyskaPiekarska E, Smiyan S, Ivanova D, Zielinska A, et al. Novel formulation of Ct-P13 for subcutaneous administration in patients with rheumatoid arthritis: initial results from a phase I/III randomised controlled trial. Ann Rheum Dis. 2018;77:315.

39 Schreiber S, Jang BI, Borzan V, Lahat A, Pukitis A, Osipenko M, et al. Novel formulation of CT-P13 (infliximab biosimilar) for subcutaneous administration: initial results from a phase 1 open-label randomized controlled trial in patients with active Crohn's disease. Gastroenterology. 2018;154(6):34477-9.

40 Lichtenstein L, Ron Y, Kivity S, Ben-Horin S, Israeli E, Fraser GM, et al. Infliximab-related infusion reactions: systematic review. J Crohns Colitis. 2015;9(9):806-15.

41 Shivaji UN, Sharratt CL, Thomas T, Smith SCL, Iacucci M, Moran GW, et al. Review article: managing the adverse events caused by antiTNF therapy in inflammatory bowel disease. Aliment Pharmacol Ther. 2019;49(6):664-80.

42 Duron C, Goutte M, Pereira B, Bommelaer G, Buisson A. Factors influencing acute infusion reactions in inflammatory bowel disease patients treated with infliximab in the era of scheduled maintenance therapy. Eur J Gastroenterol Hepatol. 2015;27(6):705-11.

43 Picoraro J, Winberry G, Siegel CA, El-Matary W, Moses J, Grossman A, et al. Premedication use before infliximab administration: a crosssectional analysis. Inflamm Bowel Dis. 2017; 23(1):174-80.
44 Farrell RJ, Shah SA, Lodhavia PJ, Alsahli M, Falchuk KR, Michetti P, et al. Clinical experience with infliximab therapy in 100 patients with Crohn's disease. Am J Gastroenterol. 2000;95(12):3490-7.

45 Kirchgesner J, Lemaitre M, Carrat F, Zureik M, Carbonnel F, Dray-Spira R. Risk of serious and opportunistic infections associated with treatment of inflammatory bowel diseases. Gastroenterology. 2018;155(2):337-e10.

46 Lichtenstein GR, Feagan BG, Cohen RD, Salzberg BA, Diamond RH, Price S, et al. Serious infection and mortality in patients with Crohn's disease: more than 5 years of followup in the TREAT ${ }^{\mathrm{mm}}$ registry. Am J Gastroenterol. 2012;107(9):1409-22.

47 Lichtenstein GR, Feagan BG, Cohen RD, Salzberg BA, Safdi M, Popp JW Jr, et al. Infliximab for Crohn's disease: more than 13 years of real-world experience. Inflamm Bowel Dis. 2018;24(3):490-501.

48 Axelrad JE, Lichtiger S, Yajnik V. Inflammatory bowel disease and cancer: the role of inflammation, immunosuppression, and cancer treatment. World J Gastroenterol. 2016; 22(20):4794-801.

49 Shelton E, Laharie D, Scott FI, Mamtani R, Lewis JD, Colombel JF, et al. Cancer recurrence following immune-suppressive therapies in patients with immune-mediated diseases: a systematic review and meta-analysis. Gastroenterology. 2016;151(1):97-e4.

50 Annese V, Beaugerie L, Egan L, Biancone L, Bolling C, Brandts C, et al. European evidence-based consensus: inflammatory bowel disease and malignancies. J Crohns Colitis. 2015;9(11):945-65.

51 Kotlyar DS, Blonski W, Diamond RH, Wasik M, Lichtenstein GR. Hepatosplenic T-cell lymphoma in inflammatory bowel disease: a possible thiopurine-induced chromosomal abnormality. Am J Gastroenterol. 2010; 105(10):2299-301.

52 Nielsen OH, Ainsworth MA. Tumor necrosis factor inhibitors for inflammatory bowel disease. N Engl J Med. 2013;369(8):754-62.

53 Cleynen I, Van Moerkercke W, Billiet T, Vandecandelaere P, Vande Casteele N, Breynaert $\mathrm{C}$, et al. Characteristics of skin lesions associated with anti-tumor necrosis factor therapy in patients with inflammatory bowel disease: a cohort study. Ann Intern Med. 2016;164(1): $10-22$.

54 Feuerstein JD, Cheifetz AS. Miscellaneous adverse events with biologic agents (excludes infection and malignancy). Gastroenterol Clin North Am. 2014;43(3):543-63.

55 Farraye FA, Melmed GY, Lichtenstein GR, Kane SV. Corrigendum: ACG clinical guideline: preventive care in inflammatory bowel disease. Am J Gastroenterol. 2017;112(7): 1208-58.

56 Mahadevan U, Robinson C, Bernasko N, Boland B, Chambers C, Dubinsky M, et al. Inflammatory bowel disease in pregnancy clinical care pathway: a report from the American gastroenterological association IBD parent- hood project working group. Am J Obstet Gynecol. 2019;220(4):308-23.

57 Peyrin-Biroulet L, Sandborn W, Sands BE, Reinisch W, Bemelman W, Bryant RV, et al. Selecting therapeutic targets in inflammatory bowel disease (STRIDE): determining therapeutic goals for treat-to-target. Am J Gastroenterol. 2015;110(9):1324-38.

58 Papamichael K, Cheifetz AS, Melmed GY, Irving PM, Casteele NV, Kozuch PL, et al. Appropriate therapeutic drug monitoring of biologic agents for patients with inflammatory bowel diseases. Clin Gastroenterol Hepatol. 2019;17(9):1655-68.e3.

59 Mitrev N, Vande Casteele N, Seow CH, Andrews JM, Connor SJ, Moore GT, et al. Review article: consensus statements on therapeutic drug monitoring of anti-tumour necrosis factor therapy in inflammatory bowel diseases. Aliment Pharmacol Ther. 2017;46(11-12): 1037-53.

60 Lega S, Phan BL, Rosenthal CJ, Gordon J, Haddad N, Pittman N, et al. Proactively optimized infliximab monotherapy is as effective as combination therapy in IBD. Inflamm Bowel Dis. 2019;25(1):134-1.

61 Drobne D, Kurent T, Golob S, Švegl P, Rajar $\mathrm{P}$, Hanžel J, et al. Optimised infliximab monotherapy is as effective as optimised combination therapy, but is associated with higher drug consumption in inflammatory bowel disease. Aliment Pharmacol Ther. 2019;49(7): 880-9.

62 Vande Casteele N, Herfarth H, Katz J, FalckYtter Y, Singh S. American gastroenterological association institute technical review on the role of therapeutic drug monitoring in the management of inflammatory bowel diseases. Gastroenterology. 2017;153(3): 835-e6.

63 Papamichael K, Cheifetz AS. Therapeutic drug monitoring in IBD: the new standardof-care for anti-TNF therapy. Am J Gastroenterol. 2017;112(5):673-6.

64 Mitrev N, Kariyawasam V, Leong RW. Editorial: infliximab trough cut-off for perianal Crohn's disease: another piece of the therapeutic drug monitoring-guided infliximab dosing puzzle. Aliment Pharmacol Ther. 2017;45(9):1279-80.

65 Yarur AJ, Kanagala V, Stein DJ, Czul F, Quintero MA, Agrawal D, et al. Higher infliximab trough levels are associated with perianal fistula healing in patients with Crohn's disease. Aliment Pharmacol Ther. 2017;45(7):93340.

66 Nguyen GC, Seow CH, Maxwell C, Huang V, Leung $\mathrm{Y}$, Jones J, et al. The toronto consensus statements for the management of inflammatory bowel disease in pregnancy. Gastroenterology. 2016;150(3):734-e1.

67 van der Woude CJ, Ardizzone S, Bengtson MB, Fiorino G, Fraser G, Katsanos K, et al. The second European evidenced-based consensus on reproduction and pregnancy in inflammatory bowel disease. J Crohns Colitis. 2015;9(2):107-24. 
68 Mariette X, Förger F, Abraham B, Flynn AD, Moltó A, Flipo RM, et al. Lack of placental transfer of certolizumab pegol during pregnancy: results from CRIB, a prospective, postmarketing, pharmacokinetic study. Ann Rheum Dis. 2018;77(2):228-33.

69 Lin YS, Cheng SW, Wang YH, Chen KH, Fang CJ, Chen C. Systematic review with meta-analysis: risk of post-operative complications associated with pre-operative exposure to anti-tumour necrosis factor agents for Crohn's disease. Aliment Pharmacol Ther. 2019;49(8):966-77.

70 Gionchetti P, Dignass A, Danese S, Magro Dias FJ, Rogler G, Lakatos PL, et al. rd European evidence-based consensus on the diagnosis and management of Crohn's disease 2016: part 2: surgical management and special situations. J Crohns Colitis. 2017;11(2):135-49.

71 Zaghiyan K, McGovern D, Fleshner P. Should biologic agents be stopped before surgery for inflammatory bowel disease? Expert Rev Gastroenterol Hepatol. 2015;9(3):269-72.

72 Lau C, Dubinsky M, Melmed G, Vasiliauskas E, Berel D, McGovern D, et al. The impact of preoperative serum anti-TNFa therapy levels on early postoperative outcomes in inflammatory bowel disease surgery. Ann Surg. 2015;261(3):487-96.

73 Holubar SD, Holder-Murray J, Flasar M, Lazarev M. Anti-tumor necrosis dactor- $\alpha$ antibody therapy management before and after intestinal surgery for inflammatory bowel disease: a CCFA position paper. Inflamm Bowel Dis. 2015;21(11):2658-72.

74 Jørgensen KK, Olsen IC, Goll GL, Lorentzen M, Bolstad N, Haavardsholm EA, et al. Switching from originator infliximab to biosimilar CT-P13 compared with maintained treatment with originator infliximab (NORSWITCH): a 52-week, randomised, doubleblind, non-inferiority trial. Lancet. 2017; 389(10086):2304-16.

75 Goll GL, Jørgensen KK, Sexton J, Olsen IC, Bolstad N, Haavardsholm EA, et al. Longterm efficacy and safety of biosimilar infliximab (CT-P13) after switching from originator infliximab: open-label extension of the NOR-SWITCH trial. J Intern Med. 2019; 285(6):653-69.

76 Müller-Ladner U, Hong S, Oh C, Taylor P. Scientific rationale behind the development and approval of biosimilar infliximab (CTP13) in Europe. Expert Rev Clin Immunol. 2015;11(Suppl 1):S5-14.

77 Lim KJ, Lee SJ, Kim S, Lee SY, Lee MS, Park YA, et al. Comparable immune function inhibition by the infliximab biosimilar CT-P13: implications for treatment of inflammatory bowel disease. J Crohns Colitis. 2017;11(5): 593-602.

78 Michetti P. Efficacy of infliximab biosimilars in patients with Crohn's disease. Lancet. 2017; 390(10111):2435

79 Ye BD, Pesegova M, Alexeeva O, Osipenko M, Lahat A, Dorofeyev A, et al. Efficacy and safety of biosimilar CT-P13 compared with originator infliximab in patients with active Crohn's disease: an international, randomised, double-blind, phase 3 non-inferiority study. Lancet. 2019;393(10182):1699707

80 Meyer A, Rudant J, Drouin J, Weill A, Carbonnel F, Coste J. Effectiveness and safety of reference infliximab and biosimilar in Crohn's disease: a French equivalence study. Ann Intern Med. 2019;170(2):99-107.

81 Doherty G, Katsanos KH, Burisch J, Allez M, Papamichael K, Stallmach A, et al. European Crohn's and colitis organisation topical review on treatment withdrawal (exit strategies) in inflammatory bowel disease. J Crohns Colitis. 2018;12(1):17-31.

82 Louis E, Mary JY, Vernier-Massouille G, Grimaud JC, Bouhnik Y, Laharie D, et al. Maintenance of remission among patients with Crohn's disease on antimetabolite therapy after infliximab therapy is stopped. Gastroenterology. 2012;142(1):63-70.e5

83 Gisbert JP, Marín AC, Chaparro M. The risk of relapse after anti-TNF discontinuation in inflammatory bowel disease: systematic review and meta-analysis. Am J Gastroenterol. 2016;111(5):632-47.

84 Gisbert JP, Marín AC, Chaparro M. Systematic review: factors associated with relapse of inflammatory bowel disease after discontinuation of anti-TNF therapy. Aliment Pharmacol Ther. 2015;42(4):391-405. 